\title{
DENTAL SEXUAL DIMORPHISM
}

\author{
Manisha Sharma ${ }^{1}$, Sameer Gupta ${ }^{2}$, Avdesh Sharma ${ }^{3}$, Vandana Bhardwaj ${ }^{4}$, Pooja Sharma ${ }^{5}$, Pradeep Kumar ${ }^{6}$ \\ ${ }^{1}$ Senior lecturer, Department of Oral \& Maxillofacial Pathology, Kanti Devi Dental College, Uttar Pradesh, India \\ ${ }^{2}$ Reader, Department of Orthodontics, Kanti Devi Dental College, Uttar Pradesh, India \\ ${ }^{3}$ Senior Lecturer, Department of Conservative \& Endodontics, PDMDC, Haryana, India \\ ${ }^{4}$ Reader, Department of Conservative \& Endodontics, PDMDC, Haryana, India \\ ${ }^{5}$ Senior Lecturer, Department of Orthodontics, Kanti Devi Dental College, Uttar Pradesh, India \\ ${ }^{6} \mathrm{PG}$ Student, Department of Orthodontics, Kanti Devi Dental College, Uttar Pradesh, India
}

\begin{abstract}
-
ABSTRACT

Objective: Forensic odontology is a lineage that deals in relation to jaws and teeth as evidence to law and justice. Tooth serves as a prime importance in the context of sex identification. (1) To investigate whether there exists any correlation between odontometric measures and sexual dimorphism. (2) To compare the inter-canine arch width of mandible. (3) To evaluate the mean value of standard mandibular canine index. Method: This study is an odontometric analysis performed intra-orally with a sample of 150 teeth (75male:75 female) on students of Kanti Devi Dental college, Mathura. Mesiodistal dimensions of mandibular right and left canine with a caliper device and statistical analysis for significance of sexual dimorphism was done with student's t test. Result: The result showed that sexual dimorphism is significant in relation to mesiodistal diameter of canine. Furthermore, there was statistical significant difference in tooth crown dimension between males and females where the males showed higher mean values. Conclusion: The study show definite statistically significant sexual dimorphism hence they can play significant role in providing expertise in civil \& criminal proceedings to ensure that forensic dentistry will remain viable component of forensic medicine.
\end{abstract}

Key words : Dental sexual dimorphism, Odontometry, Canine, Forensic.

\section{INTRODUCTION}

Identification of living person and the dead is of paramount importance in forensic practice routinely. ${ }^{1}$ Forensic dentists are usually a part of a team of identification specialist that include anthropologist and fingerprint experts, to name a few. According to Clark, almost $50 \%$ of identification in disasters are from dental evidence. Therefore, most disasters have an odontology section. ${ }^{2}$ Teeth may be used for measuring sex by measuring their mesio-distal (MD) and buccolingual (BL) dimensions. Lund and Mornstad state that "this is of special importance in young individuals where skeletal secondary sexual characters have not yet developed". "Sexual Dimorphism" refers to those differences in size, stature and appearance between male and female. ${ }^{3}$ Dental sexual dimorphism that can be applied to dental identification because no two mouths are alike (Keisu, 1990). Teeth are one of the hardest tissues in the human body and are known to resist postmortem insults. Their ability to survive fire, bacterial decomposition, severe trauma, air crash, hurricane, cataclysm, etc. makes them the best material for study. Whenever it is possible to predict the sex, identification is simplified because then only missing persons of one sex need to be considered in this sense identification of sex takes precedence over age (Camps, 1976). The study of permanent mandibular canine 
teeth offers certain advantages in that they are the least extracted teeth, are less affected by periodontal diseases, are exposed to less plaque, calculus, abrasion from brushing, and are the last teeth to be extracted with respect to age. ${ }^{4}$ These findings indicate that mandibular canines can be considered as the 'key teeth' for personal identification. $^{5}$

Considering the significance of dental sexual dimorphism in providing expertise in civil and criminal proceedings, we tried to investigate whether there exists any correlation between odontometrics measures and sexual dimorphism and reliability of these indices in determination of gender in times of need.

\section{MATERIALAND METHOD}

This cross sectional prospective study included 150 healthy volunteer students of, Kanti Devi Dental College, Mathura, Uttar Pradesh. The males and females were equally distributed and their age group ranged 19-24 years (Figure 1). The inclusion criteria were healthy individual. The significant exclusion criteria employed for selection of the study sample were malalignment, malrotation, malocclusion, spacing, missing incisor, dental restoration, dental wiring and prosthetics, and attrition. Persons suffering from chronic systemic diseases were also excluded. Impression of lower arch is taken (Figure 2, 3) and the following measurements were taken by using a digital Vernier Caliper with resolution of $0.02 \mathrm{~mm}$ directly on the study cast (Figure 4).

1. The mandibular canine width: was taken as the greatest mesio-distal width between the contact points of the teeth on either side of the lower jaw.

2. The inter-canine distance: was measured as the linear distance between the tips of right and left mandibular canine in the lower jaw.

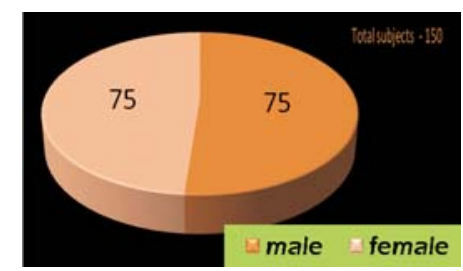

Figure 1: Pie chart showing total no of subject.

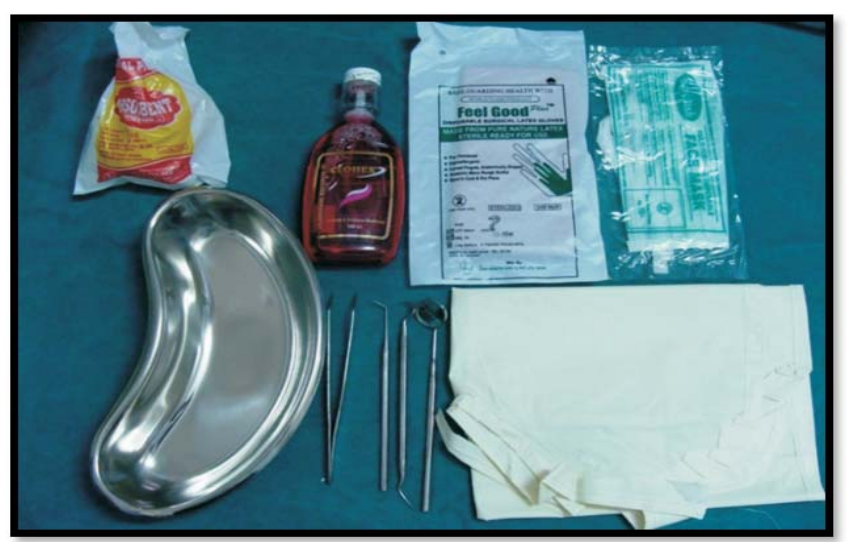

Figure 2: Armamentarium for examination of study subjects

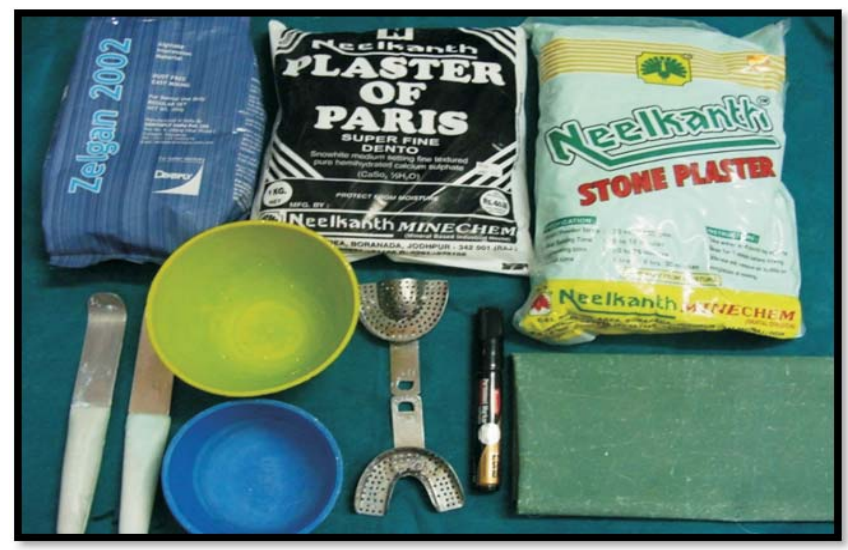

Figure 3: Armamentarium for making impression and obtaining study cast.

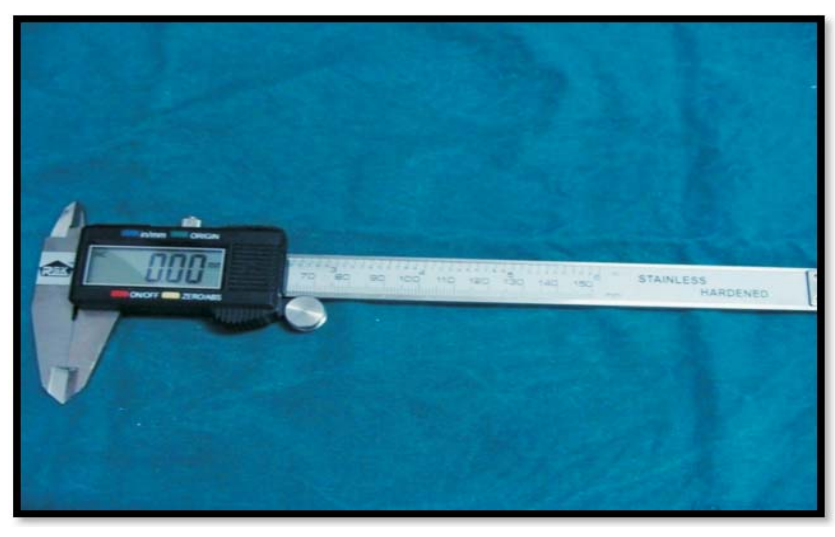

Figure 4: Digital Vernier- Calliper

Sexual Dimorphism in right and left mandibular canines was calculated using formula given by Garn \& Lewis ${ }^{6}$ as follows:

SEXUALDIMORPHISM $=(\mathrm{Xm} / \mathrm{Xf}-1) \times 100$

$(\mathrm{Xm}=$ mean value of male canine width;

$\mathrm{Xf}=$ mean value of female canine width). 
The mandibular canine indices were calculated based on the formula used by Rao et al. $^{7}$ Observed mandibular canine index (MCIo) was calculated using the formula:

Mesio-distal crown width of mandibular canine (MCIo)

\section{$=$ \\ Mandibular canine arch width or inter - canine distance}

Standard Mandibular canine index (MCIs) value was obtained from the measurements taken from the samples by applying following formula:

Standard MCI (MCIs) $=[($ Mean male MCI - SD $)+$ (Mean female MCI + SD)] / 2 MCIs value is used as a cut-off point to differentiate males from females.

Statistical Analysis: The entire data collected was subjected to statistical analysis by using computer software package SPSS/PC version 11.5. All readings obtained were subjected to sta-tistical analysis and Z-test was applied to derive conclusions and sexual dimorphism in right and left mandibular canines. Appropriate statistical analysis was also done for statistical significance of different parameters.

\section{RESULTS AND OBSERVATION}

From Table 1, it is evident that these parameters as measured for males and females when compared are found to be statistically significant. This indicates that there is existence of a statistically significant sexual dimorphism in the morphometry of the mandibular canines.

From Table 2, it can be concluded that the Mandibular Canine Index is useful in predicting sex to an extent as

\begin{tabular}{|c|c|c|c|c|c|}
\hline Parameters & Gender & $\mathbf{N}$ & Mean \pm SD & t-stat & p-value \\
\hline Right canine width & $\begin{array}{l}\text { Male } \\
\text { Female }\end{array}$ & $\begin{array}{l}77 \\
73 \\
\end{array}$ & & 9.536 & $\begin{array}{l}.004, \\
\text { significant }\end{array}$ \\
\hline Left canine width & \begin{tabular}{|l|} 
Male \\
Female
\end{tabular} & $\begin{array}{l}77 \\
73 \\
\end{array}$ & & 10.641 & $\begin{array}{l}.006, \\
\text { significant }\end{array}$ \\
\hline $\begin{array}{l}\text { Inter-canine } \\
\text { distance }\end{array}$ & \begin{tabular}{|l|} 
Male \\
Female \\
\end{tabular} & $\begin{array}{l}77 \\
73 \\
\end{array}$ & \begin{tabular}{|l|}
$.280 \pm 0$ \\
$.270 \pm 0$ \\
\end{tabular} & 2.675 & \begin{tabular}{|l|}
.008, \\
significant \\
\end{tabular} \\
\hline $\begin{array}{l}\text { Right mandubular } \\
\text { canine index }\end{array}$ & \begin{tabular}{|l|} 
Male \\
Female \\
\end{tabular} & $\begin{array}{l}77 \\
73 \\
\end{array}$ & $\begin{array}{l}0.27 \pm 0.02 \\
0.25 \pm 0.03 \\
\end{array}$ & 4.761 & $\begin{array}{l}.000, \\
\text { significant }\end{array}$ \\
\hline $\begin{array}{l}\text { Left mandubular } \\
\text { canine index }\end{array}$ & $\begin{array}{l}\text { Male } \\
\text { Female }\end{array}$ & $\begin{array}{l}77 \\
73 \\
\end{array}$ & $\begin{array}{l}0.26 \pm 0.02 \\
0.25 \pm 0.02 \\
\end{array}$ & 4.541 & $\begin{array}{l}.000, \\
\text { significant }\end{array}$ \\
\hline
\end{tabular}

Table 1 high as $70 \%$. This method was found to be more reliable in case of females.

From Table 3, depicted more sexual dimorphism in right canine than left canine.

\begin{tabular}{|l|l|l|}
\hline Gender & Right MCI & Left MCI \\
\hline Male & $64.1 \%$ & $67.5 \%$ \\
\hline Female & $64.8 \%$ & $69.79 \%$ \\
\hline
\end{tabular}

Table 2

\begin{tabular}{|l|c|c|c|}
\hline Gender & Female & Male & Sexual dimorphism \\
\hline Right canine (mm) & $5.8-7.6$ & $7.0-8.5$ & $11.30 \%$ \\
\hline Left canine (mm) & $5.8-7.5$ & $6.8-8.2$ & $10.97 \%$ \\
\hline
\end{tabular}

\section{DISCUSSION}

Forensic odontology is a vital and integral part of forensic science that is most widely utilized for identification of the living and deceased persons. In recent times, forensic odontology has evolved as a new ray of hope in assisting forensic medicine. ${ }^{8}$

Sexual dimorphism in humans is an established trend with long evolutionary history. All known hominids have exhibited skeletal and dental dimorphism to some degree." "Sexual dimorphism" refers to those differences in size, stature and appearance between male and female. It can also be applied to dental identification because no two mouths are alike.

Various methods like anatomical methods, radiological methods, nuclear sexing have been used to establish the identity of unknown remains. Because of their unique traits and characteristics teeth can be used for sex determination with the aid of odontometric analysis. Odontometric measurements provide a wealth of information relevant to human evolution and a variety of biological problems as well as to forensic and clinical odontology. 
Our study consisted of 150 healthy individuals, out of which 75 were males and 75 were females. Mesio-distal width of both mandibular canines and mandibular intercanine arch width was measured with digital vernier caliper directly on the study cast. The present study establishes the existence of a definite statistically significant sexual dimorphism in mandibualr canine. We found that maximum sexual dimorphism is exhibited by mandibular right canine $(11.30 \%)$ than left canine $(10.97 \%)$ for mesio-distal crown width. Our findings are in accordance with P.C Shrivastav $^{3}$ and Ramakant Nayak ${ }^{10}$ who also found right canine to be more sexually dimorphic than left, but contradictory to those of other Kaushal et al, Reddy et al who have reported the left mandibular canine to exhibit greater percentage of dimorphism with still higher value.

Several non-hominid primates as well as extinct hominid species also exhibit dimensional dental sexual dimorphism especially in the canines. This dimorphism is most likely as a result of evolutionary selection for intra-species or single-sex competition for mates, territory, or other resources. ${ }^{11}$ According to Thompson ${ }^{12}$ canines differ from other teeth with respect to survival and sex dichotomy. These differences probably are related to their function, which is different on an evolutionary basis from other teeth. In carnivores and in most primates, the chief function of the canines is not masticatory; their function is related to threat of aggression and actual aggression. Eimerl and DeVore ${ }^{13}$ postulated that in the evolution of primates there was a transfer of aggressive function from the canines in apes to the fingers in man, and that until this transfer was complete, survival was dependent on the canines, especially those of the males. In present day humans, it is not coincidence that the mandibular canines are the teeth that show the greatest sex difference in size and in prominence and eruption age. They are the teeth most able to survive dental disease also. The human male appears to retain canines that are masculine in form, position, and development, if not in function.

When we calculated the mandibular intercanine distance both in males and females, it was found highly significant ( $\mathrm{p}$ value $<0.01$ ). It was further observed that mean intercanine distance in males was $28.0 \pm 0.19 \mathrm{~mm}$ and the value in females was $27.0 \pm 0.22$ $\mathrm{mm}$, thus values in males being higher than those of females. Similar observations in males and females has been observed by Rao et al. (male: $29.6 \pm 0.016$, female: $25.4 \pm 0.014$ ), Kaushal et al (male: $25.873 \pm 1.253$, female: $25.070 \pm 1.197$ ), Reddy et al (male: $26.860 \pm 1.48$, female: $26.287 \pm 1.45$ ) and AlRifaiy et al (males: 27.0171 \pm 2.3168 and females: $26.4615 \pm 2.7761 \mathrm{~mm}){ }^{7,5,14,15}$

Canine indices were calculated according to the formulae given by Rao et al. ${ }^{7}$ Mean width of canine was divided by intercanine distance which showed that the canine width has a direct relationship with the canine arch width, enabling the canine index to be derived. Right mandibular canine index in males was $0.27 \pm 0.02 \mathrm{~mm}$ and the value in females was $0.25 \pm 0.03$. Left mandibular canine index in males was $0.26 \pm$ $0.02 \mathrm{~mm}$ and the value in females was $0.25 \pm 0.02$. In the present study mandibular index was statistically significant. However considering that levels of dental sexual dimorphism are shown to vary from population to population, the results may vary in other ethnic groups

\section{CONCLUSION}

Sexual dimorphism in humans is an established trend with long evolutionary history. Teeth may be used for sex determination with the aid of odontometric analysis. Odontometrics measurement provides a wealth of information relevant to human evolution and a variety of biological problems as well as to forensic and clinical odontology. We concluded that the method of using odontometrics is an 
advantageous as it is inexpensive, requires no elaborate apparatus and is suited for situations where large numbers of samples have to be analyzed for gender estimation. In addition, the measurements and derivation of the index values is rapid, involves simple mathematical calculation. This method incorporates minimal interobserver discrepancy and bias as the anatomical landmarks and measurements for the calculation of the index are easy to learn, well-defined and standard. This is acceptable in situations when the DNA technology is inaccessible or jaws are the only remnants available for investigations. Even in conditions when other skeletal remains are submitted for analysis, these indices may prove valuable as adjuncts. Odontometric measures are under considerable influence of environment. All measurements are, therefore population specific, and do not apply to the world at large. Hence further population specific studies are required to establish correlation between odontometrics and sexual dimorphism.

ACKNOWLEDGMENTS: not applicable CONFLICT OF INTEREST: not applicable

\section{REFERENCES}

1) B. Rai, R. K. Jain, J. Duhan, S. Dutta \& S. Dhattarwal. Importance Of Maxillary First Molar For Sex Determination.
The Internet Journal of Dental Science. 2007; 4 (2)

2) Shafer's Textbook of Oral Pathology, $6^{\text {th }}$ edition.pg 871-899

3) Dr. P. C. Srivastava. Correlation of Odontometric Measures in Sex Determination. J Indian Acad Forensic Med, 32(1): 56-61

4) Patterson KB, Kogan SL. Dental identification in Woodbridge disaster. J Canad Dent Assoc. 1985; 37: 301-06

5) Kaushal S, Patnaik VVG, Agnihotri G. Mandibular Canines in sex determination. J Anat Soc India. 2003; 52 (2): 119-24

6) Garn SM and Lewis AB. Bucco Lingual size asymmetry and its developmental meaning. Angle Orthod. 1967; 37(1): 186-193

7) Rao NG, Rao NN, Pai ML, Kotian MS. Mandibular canine index - A clue for establishing sex identity. Forensic Sci Int. $1989 ; 42: 249-54$

8) Chandra Shekar BR, Reddy C. Role of dentist in person identification. Indian J Dent Res 2009; 20:356-60

9) Pretty IA, Sweet D. A look at forensic dentistry - Part 1: The role of teeth in the determination of human identity, British Dental Journal, 2001; 190 (7): 359-66

10) Nayak Ramakant. Validity of Deciduous Canines in Sex Determination in South Indian Population - An Observational Study. JIDA 2011; 5 (2): 266-269

11) Morgan Johanna, Metric Sexual Dimorphism in Permanent Canines Bull Int Assoc Paleodont, 2011; 5(1):4-12

12) Anderson DL. Interrelationships and Sex Differences of Dental and Skeletal Measurements. J Dent Res 1973; 52: 431

13) Eimerl S, Devore I. The Primates, New York: Time Inc., 1965

14) Al-Rifaiy MQ. Dimorphism of mandibular and maxillary canine teeth in establishing sex identity The Saudi Dental Journal 1997; 9 (1): 17-20

15) Reddy VM, Saxena S, Bansal P. Mandibular canine index as a sex determinant: A study on the population of western Uttar Pradesh. J Oral Maxillofac Pathol 2008; 12:56-9 